\title{
The impact of eLearning on health professional educators' attitudes to information and communication technology
}

This article was published in the following Dove Press journal:

Journal of Multidisciplinary Healthcare

29 January 2015

Number of times this article has been viewed

\author{
Victoria Neville \\ Mary Lam² \\ Christopher J Gordon ${ }^{3}$ \\ 'Faculty of Science, Medicine and \\ Health, The University of Wollongong, \\ Wollongong, NSW, Australia; ${ }^{2}$ Faculty \\ of Health Science, ${ }^{3}$ Sydney Nursing \\ School, The University of Sydney, \\ Sydney, NSW, Australia
}

Background: The use of information and communication technology (ICT) in health professional education is increasing rapidly. Health professional educators need to be responsive to health professionals' information and communication technological needs; however, there is a paucity of information about educators' attitudes to, and capabilities with, ICT.

Methods: Fifty-two health professional educators, enrolled in health professional education postgraduate studies, participated in an online subject with specific eLearning components requiring the use of ICT. They completed a pre- and postquestionnaire pertaining to ICT attitudes, confidence, and usage.

Results: Participants reported significant increases in overall ICT confidence during the subject despite it being high at baseline (mean: 7.0 out of $10 ; P=0.02$ ). Even with increased ICT confidence, there were decreases in the participants' sense of ICT control when related to health professional education $(P=0.002)$; whereas, the amount of time participants engaged with ICT devices was negatively correlated with the sense of ICT control $(P=0.002)$. The effect of age and health discipline on ICT attitudes and confidence was not significant $(P>0.05)$.

Conclusion: This study reports that health professional educators have perceptual deficits toward ICT. The impact of eLearning increased confidence in ICT but caused a reduction in participants' sense of control of ICT. Health professional educators require more ICT training and support to facilitate better ICT integration in health professional education settings.

Keywords: confidence, sense of control

\section{Introduction}

eLearning is concerned with the learning activities, resource access, communication, and assessment undertaken in an online environment. This type of learning environment normally uses a range of information and communication technologies (ICTs) accessible via computer or mobile devices. The purpose of this study was to explore the attitudes of health professional educators (HPEs) toward their use of ICT, in general, and within their educational practice, in particular. The term "ICT," within this paper, refers to the technologies used in eLearning,

HPEs are health care practitioners who undertake the role of teacher for their professional peers, students in preregistration courses, or patients. HPEs facilitate learning for practice, from practice, and in practice within clinical, community, professional organization, or higher education contexts. A key role of HPEs, in facilitating learning and professional development, is their modeling of good professional practice ${ }^{1}$

including using ICT., ${ }^{2,3}$
Correspondence: Victoria Neville Faculty of Science, Medicine and Health, The University of Wollongong,

Wollongong, NSW 2522, Australia

Tel +6I 2422 I 3469

Email vicnev@uow.edu.au

Christopher J Gordon

Sydney Nursing School M02,

The University of Sydney, Sydney,

NSW 2006 Australia

Email christopher.gordon@sydney.edu.au

submit your manuscript $\mid$ www.dovepress.com 
Systematic reviews of research literature on eLearning and web-based learning in health professional education reveal a focus on the strategies and tools of eLearning used by HPEs and learning outcomes achieved through eLearning. ${ }^{4,5}$ Button et al' $\mathrm{s}^{6}$ recent review of the literature of eLearning and ICT in nursing education identified issues relevant to eLearning for nursing educators. These issues, however, emphasized knowledge or skill development, rather than attitudes, which were of concern to educators, such as the time for eLearning resource development and facilitation and the need for eLearning ICT skills training.

Studies that address the affective areas of eLearning in health professional education tend to focus on participants' attitudes to $\mathrm{ICT}^{7-11}$ or their satisfaction with the eLearning experience. ${ }^{12,13}$ Childs et a ${ }^{14}$ conducted a systematic review of the health professional education literature to identify the barriers and solutions to eLearning for health professionals and students. The findings of this review identified institutional, management, learner, and HPE issues. The attitudinal issues of HPEs to eLearning included resistance to change, poor motivation, fear, anxiety, and low confidence with computers.

Confidence in being able to successfully complete learning tasks has an important role in learner achievement. ${ }^{15} \mathrm{We}$ might expect, therefore, that HPEs learning to use ICT within eLearning will also depend on their sense of confidence with ICT. Cooper's ${ }^{16}$ study found that intrinsic motivation and satisfaction with eLearning were the primary incentives for educators in higher education. This internal source of motivation suggests that an internal locus of control supports HPEs' confidence in learning to use ICT within eLearning.

In this sense, locus of control refers to the extent to which people believe that they are in control of events that occur in their environment. ${ }^{17}$ People with an internal locus of control are more likely to believe that their own actions can affect environmental events, including their learning achievement. ${ }^{18}$ Conversely, people with an external locus of control are more likely to feel acted upon or controlled by their environment. Wishart and Ward ${ }^{19}$ found that a feeling of being in control of ICT, rather than being controlled by it, was linked with nursing students being less fearful of the technology. This suggests that the role of locus on control in an eLearning environment may also apply to HPEs who grapple with their motivation and confidence with eLearning ICT.

The influence of educator attitudes toward the use of ICT in eLearning on learner satisfaction with eLearning is demonstrated by previous studies. ${ }^{20-23}$ This signifies the important role that HPEs play in enabling opportunities for learner development, through eLearning, of thinking skills and selfefficacy with ICT that are transferable to professional practice settings. ${ }^{24,25}$ The relationship between attitudes and behaviors has long been recognized as complex. ${ }^{26}$ Nevertheless, encouraging HPEs to adopt the desired behaviors of using ICT in their educational practice requires that they develop their intention to act in the desired way. ${ }^{7}$ This intention to act is influenced by the attitudes toward the use of ICT in eLearning practice that HPEs develop.

HPEs differ from many of their peers by being both clinical practitioners and educators. Therefore, HPEs' attitudes to ICT for educational practice might be influenced by their exposure to, and expected use of, ICT in their professional contexts with different ICT requirements, such as educational or clinical contexts. ${ }^{27}$ Accordingly, we sought information to identify factors and their degree of influence, which may contribute to HPE attitudes toward to ICT in eLearning.

\section{Methods}

This study was conducted at a major metropolitan Australian university that has a diverse range of undergraduate and postgraduate health professional disciplinary degrees. Health professional education, a major postgraduate degree stream, enrolled HPEs from a variety of health disciplines. The postgraduate health professional education course consisted of four mandatory subjects, two of which were delivered using online learning with a suite of elective subjects. Each subject equated to approximately 120 hours of learning, and the mandatory subjects were conducted within the same year prior to the elective components. The content of each subject offered via eLearning was related to health professional education pedagogy (clinical teaching and supervision and simulation-based learning for HPEs) with an emphasis on the incorporation of ICT into health professional education. Students enrolled in these subjects were required to complete a range of online learning activities and assignments which necessitated substantial engagement with ICT. These eLearning activities included viewing online videos and documents, sharing ideas by communicating in discussion forums, creating blended media online presentations, and submitting written assignments online. Students were encouraged to use a range of ICT devices including computers, smart phones, and tablets to get access to and complete the eLearning activities. In this way, all students enrolled in these two subjects were exposed to learning about health professional education within ICT-rich eLearning environments. Prior to undertaking the study, we determined the sample size on the 
assumption that the study would provide $80 \%$ power with a type one error of 5\%, an attrition rate of 5\%, and $5 \%$ for the adjustment for covariates. This revealed that a sample size of 52 participants was required.

\section{Participants}

Participants were HPEs enrolled in the health professional education postgraduate course. Fifty-six HPEs were recruited into the study. All participants were enrolled at different stages of their degrees; however, all had completed at least two subjects which were conducted in face-to-face modality prior to undertaking the subject via eLearning. We only included participants without prior eLearning exposure during their studies to ascertain the effect of eLearning with the subjects. If participants completed both online subjects, data were analyzed only from the first subject studied by the participants. Due to incomplete surveys and students withdrawing from the subject, $\mathrm{n}=52$ participants completed the study (Table 1).

\section{Ethical approval}

Ethical approval was granted by the Human Research Ethics Committee of the university, and all participants consented to the study prior to the commencement of the subjects.

\section{Procedures}

Participants completed a questionnaire related to ICT attitudes, experiences, and knowledge and confidence with ICT. The questionnaire was administered twice, prior to and on completion of the subject. It was undertaken in an electronic format following consent. All participants were deidentified. Participants were required to complete the prequestionnaires within the first 2 weeks of the semester and the postquestionnaires within 2 weeks of subject completion. All questions needed to be completed before submission.

Table I Participant demographics $(n=52)$

\begin{tabular}{ll}
\hline Age, $\mathrm{n}(\%)$ & \\
Less than 35 years & $33(63.5)$ \\
35 years and older & $19(36.5)$ \\
Female, $\mathrm{n}(\%)$ & $40(76.9)$ \\
Health profession, $\mathrm{n}(\%)$ & \\
Medical doctor & $8(15.4)$ \\
Registered nurse & $24(46.2)$ \\
Allied health* & $20(38.5)$ \\
Workplace, $\mathrm{n}(\%)$ & \\
Public hospital & $36(69.2)$ \\
Nonpublic settings & $12(23.1)$ \\
University & $4(7.7)$ \\
\hline
\end{tabular}

Note: *Allied health profession comprises medical radiation practitioner, occupational therapist, physiotherapist, and speech therapist.

\section{Instruments}

Participants completed a questionnaire about attitudes to ICT. The Information Technology Attitude Scales for Health $(\text { ITASH })^{28}$ was developed previously to ascertain health professionals' attitudes toward ICT. The questionnaire was validated in 151 health professionals, but none were identified as HPEs. It consists of three subscales, efficiency of care (A); education, training, and development (B); and the control scale $(\mathrm{C})$, which show robust reliability (Cronbach's alpha scores: $0.88,0.70,0.77$ for the three subscales, respectively) and construct validity established previously. ${ }^{28}$ The efficiency of care subscale explored health professionals' attitudes to ICT improving health care while the education, training, and development subscale related to the amount and quality of ICT education and training the health professional received; and the control subscale was indicative of the health professionals sense of control over ICT. The control subscale addressed the extent to which HPEs felt that they were in control of their own ability to use ICT. We modified the ITASH subscales to match the needs of the participant cohort. The subscales were contextualized for the HPE and the health professional education domain (Table 2).

\section{Data analysis}

All descriptive statistics were reported as means, standard deviations, and ranges, where applicable. Cronbach's alphas were calculated to quantify internal consistency, with scores $\geq 0.7$ considered satisfactory. ${ }^{29}$ When considering the entire data set, the pre-, postsubject ITASH subscale aggregated scores (efficiency of care [A]; education, training, and development [B]; and control scale [C]) were analyzed using paired Student's $t$-tests. As this study was exploratory, we sought to determine if relationships between the independent variables (age groups, health professional discipline, hours of ICT usage, and time) and the dependent variables (change in ITASH subscales and self-reported confidence) existed. This was based on previous research, which has shown age and discipline to impact on health professionals attitudes to ICT. ${ }^{11,30,31}$ Student $t$-tests were used to determine the effect of age ( $<35$ years and $\geq 35$ years) and time (pre-, postsubject), and one-way analysis of variance to compare the different health professional disciplines (medical, nursing, and other disciplines combined) on changes in attitude and self-reported confidence. Pearson's correlation was used to analyze the relationship between hours of usage of ICT and attitudes and self-reported confidence at baseline. Statistical significance was set at alpha $<0.05$ for all analyses. 
Table 2 The internal consistency of Information Technology Attitude Scales for Health subscales of efficiency of care (A); education, training, and development (B); and the control scale (C)

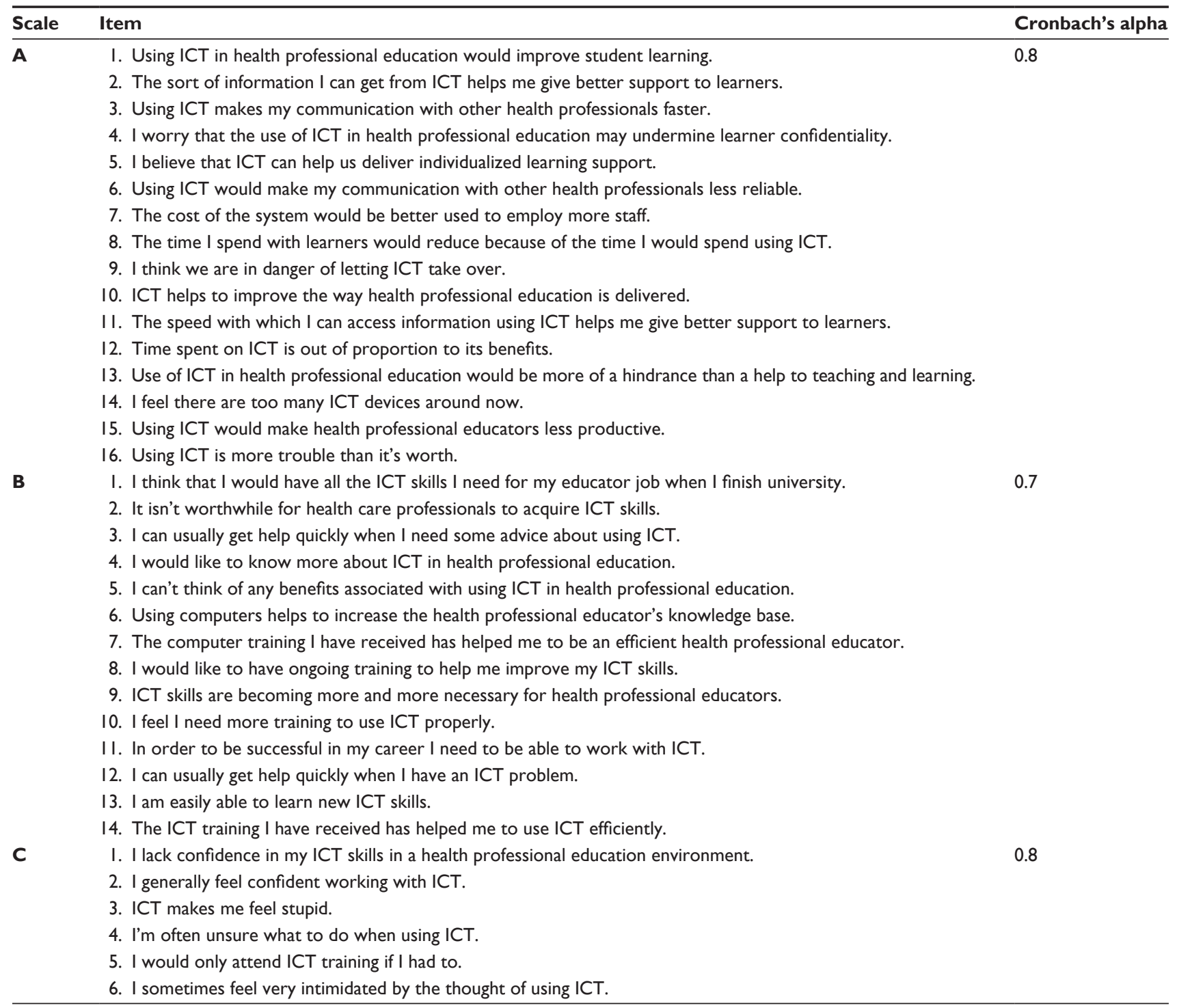

Abbreviation: ICT, information and communication technology.

\section{Results}

The participant cohort was derived from two separate mandatory online subjects, and our analysis determined that there were no significant differences between the two subject groups for age groups, health discipline, ICT usage, or mean scores for the ITASH subscales and self-reported confidence $(P>0.05)$. Accordingly, we combined the two participant groups for all subsequent analyses.

The Cronbach's alpha for the ITASH subscales A, B, and C were $0.7,0.7$, and 0.8 , respectively, indicating that the scale had strong internal consistency (Table 2). These were similar to those reported by the original tool validation.

The percentage of participants with ICT devices are shown in Figure 1. Generally, desktop or laptop computers were the most prevalent, with over $75 \%$ of participants regularly using a smartphone.

Participants reported significant increases in overall confidence during the online subject $(P<0.05)$ (Table 3 ). There were no significant differences in the ITASH efficiency of health professional education (A) and education, training, and development (B) subscales during the subject $(P>0.05)$ (Table 3 ). However, ITASH control (C) subscale, indicative of the participant's sense of ICT control, significantly declined during the subject, suggesting that despite an increase in overall ICT confidence, the participants did not feel that they were in control of ICT when related to health professional education $(P=0.002)$.

There were no statistical differences between the independent variable of age groups and different health disciplines 


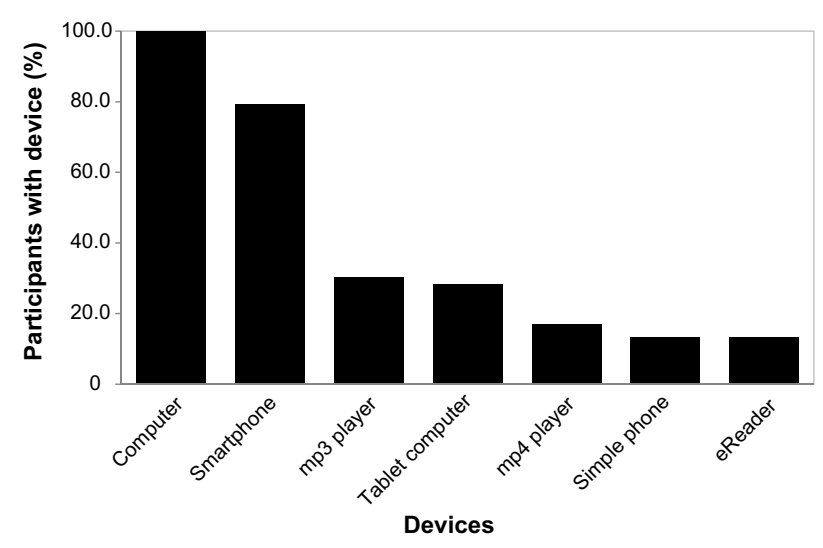

Figure I The percentage of participants with different information and communication technology devices.

and the dependent variables (ITASH subscale change and self-reported overall confidence; $P>0.05$ ).

There were significant negative correlations between the amount of time engaged with ICT devices and ITASH control (C) subscale and positive correlations for selfreported overall confidence $(P=0.002$ and $P=0.001$, respectively) (Table 4).

\section{Discussion}

The main findings from the study reveal that HPEs do not feel in control of ICT educational capacity despite reporting an increase in confidence in ICT usage. These are novel findings for two reasons. First, health care professionals are increasingly required to engage in ICT within health care settings, and HPEs need to be confident and in control in their ICT usage to support their educational endeavors. This study demonstrates that when HPEs engage in eLearning related to health professional pedagogy, they feel less in control.

Table 3 The change in Information Technology Attitude Scales for Health subscales and self-reported overall confidence scores during the online subject

\begin{tabular}{lll}
\hline Variable & $\begin{array}{l}\text { Mean difference } \\
(95 \% \mathbf{C l})\end{array}$ & Paired $t$-test \\
\hline $\begin{array}{l}\text { ITASH subscale A } \\
\text { post }- \text { pre }\end{array}$ & $-0.69(-1.8 I$ to 0.44$)$ & $t=-1.23, d f=44, P=0.224$ \\
$\begin{array}{l}\text { ITASH subscale B } \\
\text { post }- \text { pre }\end{array}$ & $-0.38(-1.45$ to 0.70$)$ & $t=-0.7 I, d f=44, P=0.482$ \\
$\begin{array}{l}\text { ITASH subscale C } \\
\text { post }- \text { pre }\end{array}$ & $-0.96(-1.55$ to -0.36$)$ & $t=-3.22, d f=44, P=0.002^{*}$ \\
$\begin{array}{l}\text { Confidence } \\
\text { post - pre }\end{array}$ & $0.50(0.08$ to 0.92$)$ & $t=2.40, d f=45, P=0.020^{*}$ \\
\hline
\end{tabular}

Notes: Subscale A, efficiency of care; subscale B, education, training, and development; and subscale $\mathrm{C}$, control. *Represents significant difference.

Abbreviations: $\mathrm{Cl}$, confidence interval; ITASH, Information Technology Attitude Scales for Health.
Second, confidence per se does not assist with improving attitudes to ICT, especially as related to usage and value of ICT for eLearning.

The improvement in HPEs' confidence in using ICT as a result of their learning experience is consistent with research into the effects of training on ICT user confidence. ${ }^{32,33}$ The concurrent decrease in the sense of user control of ICT suggests that HPEs' confidence in using ICT for their own learning may not necessarily result in the integration of ICT into their pedagogical practices. Attitudes toward learning to use ICT, in general, and attitudes toward using ICT within health professional education practice appear to be distinct issues. Further research is required to shed light on how both of these attitudinal areas may need to be addressed in the preparation of HPEs.

This study found that there were no significant differences in attitudes between age groups or between health care discipline groups. This contrasts with others exploring the attitudes of health care professionals to ICT. ${ }^{11,30,31}$ This may be because different health care disciplines may have different needs in their use of ICT for professional health care practice. ${ }^{34}$ Health professional roles, therefore, direct how ICT is used to perform those roles. In contrast, the educational roles of planning, resource development, implementation, and facilitation of learning, assessment of learning, and program evaluation are common to all educational environments, regardless of the health care discipline. Consequently, there is likely to be less difference in attitudes toward ICT for educational purposes across HPEs from different disciplines.

We found that the time spent engaging with ICT devices was related to ICT confidence and a decrease in user control. The ownership and confidence in using ICT devices of the participants in this study were similar to previous research, ${ }^{35}$ demonstrating that our cohort was representative of health professionals (Figure 1). HPEs' increased confidence in using ICT appears to be a logical consequence of the more time they spent using ICT devices. However, ICT device engagement was negatively correlated with HPEs' sense of control of ICT in general, not just with ICT devices. This suggests that exposing HPEs to more ICT devices may not be sufficient for HPEs to improve their sense of control over ICT. Instead, HPEs may need to develop a better general understanding of ICT and explore fewer devices in depth, particularly in terms of their use for learning and teaching. This is also recommended by Skiba et al. ${ }^{3}$ Developing a better general understanding of ICT for eLearning may improve their sense of control of ICT for eLearning. 
Table 4 Correlations between the amount of time spent engaged with ICT devices and Information Technology Attitude Scales for Health subscales and self-reported overall confidence at baseline

\begin{tabular}{lllll}
\hline & $\begin{array}{l}\text { Baseline ITASH } \\
\text { subscale A }\end{array}$ & $\begin{array}{l}\text { Baseline ITASH } \\
\text { subscale B }\end{array}$ & $\begin{array}{l}\text { Baseline ITASH } \\
\text { subscale C }\end{array}$ & $\begin{array}{l}\text { Self-reported } \\
\text { overall confidence }\end{array}$ \\
\hline Amount of time spent engaged with ICT devices & & & $0.45 I$ \\
$r$ & -0.184 & -0.165 & -0.415 & $0.00 I^{*}$ \\
$P$-value & 0.193 & 0.243 & $0.002^{*}$ & 52 \\
$\mathrm{n}$ & 52 & 52 & 52 & \\
\hline
\end{tabular}

Notes: Subscale A, efficiency of care; subscale B, education, training, and development; and subscale C, control. *Represents significant difference.

Abbreviations: ICT, information and communication technology; ITASH, Information Technology Attitude Scales for Health.

HPEs are usually considered to have greater clinical expertise than those they teach. The "HPE as expert" selfconcept may be undermined by a low sense of ICT control. Consequently, HPEs may not engage with ICT for eLearning. Our study found that this was common across the health care disciplines. This suggests that a sense of ICT control may be related to individual intrinsic properties rather than discipline-specific engagement.

The HPEs in this study experienced the use of ICT to learn content related to the design and practice of clinical teaching and supervision and clinical simulation, including embedding ICT into their eLearning practices. The difference in confidence with using ICT and the sense of user control of ICT as a result of the learning experience suggests that HPEs may not have been able to manage the cognitive load ${ }^{36}$ required by the content and learning experience. Consequently, HPEs may have responded by adopting a multifaceted approach to learning, ${ }^{37}$ implementing a deeper approach to learning of subject content and a more surface approach to the eLearning use of ICT. Further research is required to explore the relationships between cognitive load, approach to learning, and attitudes to ICT adopted by HPEs within similar ICT-embedded eLearning environments. In this way, HPEs may have experience in incorporating ICT into their educational repertoire and improve their sense of ICT control.

Metacognition is a significant component of the cognitive load requirements for HPEs engaged in the eLearning environments within this study. ${ }^{38}$ Thinking about how their own ICT-embedded eLearning experience assisted them to develop the declarative and procedural knowledge ${ }^{39}$ of the subject content may enable HPEs to synthesize better their knowledge and attitudes toward the use of ICT within health care professional education. To date, exploration of the relationships between metacognitive ability and attitudinal development of HPEs in relation to the use of ICT in health care professional education has not been examined and warrants further study.

\section{Limitations}

We undertook a power analysis and determined sample size prior to the study. The distribution of different health professional disciplines, however, may have had an impact on the findings despite the numerical distribution of disciplines indicative of clinical environments. Participants in this study were HPEs enrolled in subjects concerned with educational practice relevant to health care professional education. Participants were engaged in their student role throughout this study. This may have an impact on the external validity of the current findings to HPEs in nonstudent roles.

\section{Conclusion}

This study shows that HPEs' attitudes to ICT for eLearning are improved in terms of their confidence with ICT, but not their sense of control, when exposed to an eLearning environment specifically designed to address ICT-embedded pedagogy for learning about health care professional educational issues. Further research is needed to investigate issues, such as cognitive load and metacognition, which may have an impact on HPEs' sense of control in their use of ICT in their educator roles.

\section{Disclosure}

The authors report no conflicts of interest in this work.

\section{References}

1. Schumacher DJ, Englander R, Carraccio C. Developing the master learner: applying learning theory to the learner, the teacher, and the learning environment. Acad Med. 2013;88(11):1635-1645.

2. Axley L. The integration of technology into nursing curricula: supporting faculty via the technology fellowship program. Online Journal of Issues in Nursing. 2008;13(3).

3. Skiba DJ, Connors HR, Jeffries PR. Information technologies and the transformation of nursing education. Nurs Outlook. 2008;56(5):225-230.

4. Cook DA, Levinson AJ, Garside S, Dupras DM, Erwin PJ, Montori VM. Instructional design variations in internet-based learning for health professions education: a systematic review and meta-analysis. Acad Med. 2010;85(5):909-922. 
5. Lahti M, Hätönen H, Välimäki M. Impact of e-learning on nurses' and student nurses knowledge, skills, and satisfaction: a systematic review and meta-analysis. Int J Nurs Stud. 2014;51(1):136-149.

6. Button D, Harrington A, Belan I. E-learning and information communication technology (ICT) in nursing education: A review of the literature. Nurse Educ Today. 2014;34(10):1311-1323.

7. Aggelidis VP, Chatzoglou PD. Using a modified technology acceptance model in hospitals. Int J Med Inform. 2009;78(2):115-126.

8. Dawidowski AR, Toselli L, Luna DR, Oberti PF, Soto MA, de Quirós FG [Changes in physicians' attitudes to computerized ambulatory medical record systems: a longitudinal qualitative study]. Gac Sanit. 2007;21(5):384-389. Spanish.

9. Eley R, Soar J, Buikstra E, Fallon T, Hegney D. Attitudes of Australian nurses to information technology in the workplace: a national survey. Comput Inform Nurs. 2009;27(2):114-121.

10. Flores-Mir C, Palmer NG, Northcott HC, Khurshed F, Major PW. Perceptions and attitudes of Canadian dentists toward digital and electronic technologies. J Can Dent Assoc. 2006;72(3):243.

11. Huryk LA. Factors influencing nurses' attitudes towards healthcare information technology. J Nurs Manag. 2010;18(5):606-612.

12. McVey G, Gusella J, Tweed S, Ferrari M. A controlled evaluation of web-based training for teachers and public health practitioners on the prevention of eating disorders. Eat Disord. 2009;17(1):1-26.

13. Tsai SL, Tsai WW, Chai SK, Sung WH, Doong JL, Fung CP. Evaluation of computer-assisted multimedia instruction in intravenous injection. Int J Nurs Stud. 2004;41(2):191-198.

14. Childs S, Blenkinsopp E, Hall A, Walton G. Effective e-learning for health professionals and students - barriers and their solutions. A systematic review of the literature - findings from the HeXL project. Health Info Libr J. 2005;22(Suppl 2):20-32.

15. Bandura A. A social cognitive theory of action. In: Forgas JP, Innes MJ, editors. Recent Advances in Social Psychology: An International Perspective. North Holland: Elsevier; 1989:127-138.

16. Cooper C. A study of faculty attitudes, perceptions, resistance and expectations toward teaching web-based learning courses in higher education. In: McFerrin K, Weber R, Carlsen R, Willis DA, editors. Society for Information Technology and Teacher Education International Conference. 2008; Las Vegas, Nevada, USA: AACE; 2008.

17. Kormanik MB, Rocco TS. Internal versus external control of reinforcement: a review of the locus of control construct. Human Resource Development Review. 2009;8(4):463-483.

18. Fazey DMA, Fazey JA. The potential for autonomy in learning: perceptions of competence, motivation and locus of control in first-year undergraduate students. Stud High Educ. 2001;26(3):345-361.

19. Wishart J, Ward R. Individual differences in nurse and teacher training students' attitudes toward and use of information technology. Nurse Educ Today. 2002;22(3):231-240.

20. Piccoli G, Ahmad R, Ives B. Web-based virtual learning environments: a research framework and a preliminary assessment of effectiveness in basic IT skills training. MIS Quarterly. 2001;25(4):401-426.

21. Smeets E. Does ICT contribute to powerful learning environments in primary education? Comput Educ. 2005;44:343-355.

22. Sun PC, Tsai RJ, Finger G, Chen YY, Yeh D. What drives a successful e-Learning? An empirical investigation of the critical factors influencing learner satisfaction. Comput Educ. 2008;50(4):1183-1202.
23. Webster J, Hackley P. Teaching effectiveness in technology-mediated distance learning. Acad Manage J. 1997;40(6):1282-1309.

24. Bembridge E, Levett-Jones T, Jeong SY. The transferability of information and communication technology skills from university to the workplace: a qualitative descriptive study. Nurse Educ Today. 2011;31(3):245-252.

25. Jensen R, Meyer L, Sternberger C. Three technological enhancements in nursing education: informatics instruction, personal response systems, and human patient simulation. Nurse Educ Pract. 2009;9(2):86-90.

26. Ajzen I, Fishbein M. Understanding Attitudes and Predicting Social Behavior. Englewood Cliffs, NJ: Prentice-Hall; 1980.

27. Sword TS. The transition to online teaching as experienced by nurse educators. Nurs Educ Perspect. 2012;33(4):269-271.

28. Ward R, Pollard K, Glogowska M, Moule P. Information Technology Attitude Scales for Health (ITASH): Project Report. Bristol: Faculty of Health and Social Care, University of the West of England; 2006. Available from: http://hsc.uwe.ac.uk/net/research/Data/Sites/1/ GalleryImages/Research/ITASH\%20Report(1).PDF. Accessed June 15, 2011.

29. Streiner DL, Norman GR. Health Measurement Scales: A Practical Guide to Their Development and Use. 3rd ed. Oxford: Oxford University Press; 2003.

30. Darr A, Harrison MI, Shakked L, Shalom N. Physicians' and nurses' reactions to electronic medical records. Managerial and occupational implications. J Health Organ Manag. 2003;17(5):349-359.

31. Jacko JA, Sears A, Sorensen SJ. Framework for usability: healthcare professionals and the Internet. Ergonomics. 2001;44(11):989-1007.

32. Kuiper R. Metacognitive factors that impact student nurse use of point of care technology in clinical settings. Int J Nurs Educ Scholarsh. 2010;7:Article5.

33. Zdanuk S, Gimpel J, Uhanova J, Kaita KD, Minuk GY. The impact of medical informatics on the confidence of rural physicians caring for patients with chronic hepatitis C viral infections. Fam Pract. 2001;18(6):602-604.

34. Ammenwerth E, Mansmann U, Iller C, Eichstädter R. Factors affecting and affected by user acceptance of computer-based nursing documentation: results of a two-year study. J Am Med Inform Assoc. 2003;10(1):69-84.

35. Eley R, Fallon T, Soar J, Buikstra E, Hegney D. Nurses' confidence and experience in using information technology. Aust J Adv Nurs. 2008;25(3):23-35.

36. Sweller J. Cognitive load theory, learning difficulty and instructional design. Learn Instr. 1994;4:295-312.

37. Entwistle N. Approach to learning and forms of understanding. In: Dart BC, Boulton-Lewis G, editors. Teaching and Learning in Higher Education. Melbourne, Australia: ACER Press; 1998:72-101.

38. Wilson NS, Bai H. The relationships and impact of teachers' metacognitive knowledge and pedagogical understandings of metacognition. Metacognition and Learning. 2010;5(3):269-288.

39. Eraut M. Developing Professional Knowledge and Competence. London: Routledge Falmer; 1994.
Journal of Multidisciplinary Healthcare

\section{Publish your work in this journal}

The Journal of Multidisciplinary Healthcare is an international, peerreviewed open-access journal that aims to represent and publish research in healthcare areas delivered by practitioners of different disciplines. This includes studies and reviews conducted by multidisciplinary teams as well as research which evaluates the results or conduct of such teams or

\section{Dovepress}

healthcare processes in general. The journal covers a wide range of areas and welcomes submissions from practitioners at all levels, from all over the world. The manuscript management system is completely online and includes a very quick and fair peer-review system. Visit http://www.dovepress.com/testimonials.php to read real quotes from published authors. 